\title{
Using of lactate dehydrogenase and Gamma glutamyl transpeptidase as routine screening test among patients with breast cancer
}

\author{
Zahra A Ahmed ${ }^{1}$, Abd Elkareem A Rabo ${ }^{1}$ and Asaad Ma. Babker ${ }^{2, *}$ \\ 1 Department of Clinical Chemistry, Faculty of Medical Laboratory Sciences, University of Al-Neelain, Khartoum, Sudan. \\ 2 Department of Medical Laboratory Sciences, College of Health Sciences, Gulf Medical University, Ajman, UAE.
}

Publication history: Received on 02 December 2019; revised on 16 December 2019; accepted on 17 December 2019

Article DOI: https://doi.org/10.30574/gscbps.2019.9.3.0229

\begin{abstract}
Breast cancer is cancer that forms in the cells of the breasts. After skin cancer, breast cancer is the most common cancer diagnosed in women in the United States. Breast cancer can occur in both men and women, but it's far more common in women. Aim of this study to evaluate the lactate dehydrogenase and Gamma glutamyl transpeptidase as screening tests among women with breast cancer. Fifty women diagnosed with breast cancer were involved in this cross-sectional study, they were attended to Khartoum oncology hospital for diagnosis, treatment and follow up. They were grade I, II and III. Approval of study to be performed was obtained from each patient and hospital administration as well. Under hygienic condition blood withdrawn in plane containers from each subject considering labeling and data obtained from each one, blood allowed for clot formation and subsequent serum separation which preserved at $20{ }^{\circ} \mathrm{C}$ for later chemical analysis. Chemical analysis targeted enzymes, GGT, LDH and ALP, they measured by means of spectrophotometer method, using Biosystem device, reagents were Biosystem trademark, they were ready to use. This study conducted in concern of breast cancer, it involved 50 women with established diagnosis, the Mean \pm SD duration of the disease was $(3.52+1.89)$ years and their age Mean \pm SD was $(38.1+6.31)$ year's .They were enrolled in the measurement of GGT and LDH Comparing the levels of measured parameters with normal value for each one, brought significant difference for LDH and ALP. Enzymes level among the three grades of breast cancer brought significant difference for LDH at grade II and III as p values 0.022 and 0.001 respectively, while GGT has only significant difference at grade III as p value 0.022 . Significant elevation in serum levels of lactate dehydrogenase and Gamma glutamyl transpeptidase among patients with breast cancer and suggest that the estimation of both can be used as routine screening tests in all suspected carcinoma breast patients.
\end{abstract}

Keywords: Lactate dehydrogenase; Gamma glutamyl transpeptidase; Breast cancer; Screaming test

\section{Introduction}

Globally, breast cancer is the second most frequently diagnosed malignancy just behind lung cancer, accounting for over two million cases each year. It is also the leading cause of cancer death in women worldwide. In the United States, breast cancer is the most common female cancer, the second most common cause of cancer death in women [1, 2, 3] . Breast cancer deaths have decreased by one third or more over the past three decades. This is due in part to increased screening, as well as earlier and improved treatment for breast cancer. Screening usually detects the disease at an earlier stage, when the chances of successful treatment are higher. Early detection and treatment of breast cancer improve survival because the breast tumor can be removed before it has a chance to spread (metastasize) [4]. Breast cancer characterized by prevalence, aggressiveness, unequal geographic distribution, and an increasing incidence throughout the world [5] .Many experimental, clinical and epidemiological studies have revealed that several factors influence breast cancer etiology. Hormonal factors [7], reproductive factors, genetic factors, lifestyle, and dietary

\footnotetext{
${ }^{*}$ Corresponding author

E-mail address: azad.88@hotmail.com
} 
factors [8]. Lactate dehydrogenase (LDH) is the enzyme responsible for the conversion of pyruvate to lactate during glycolysis [9]. It is expressed in all tissues and its A and B subunits, coded by two different genes LDH-A and LDH-B, combine to construct five iso-enzymes (LDH1 to LDH5) with selective distribution among tissues and in serum [10]. Elevated LDH levels are seen in cancer patients, and its prognostic value has been shown in several malignancies such as germ cell tumors, lymphoma, melanoma and renal cell carcinoma [11,12]. Gamma-glutamyltransferase (GGT) is a cell-membrane bound enzyme [13], GGT is responsible for the glutathione (GSH) metabolism, catalyzing the degradation of extracellular GSH and further promoting amino-acid recovery for subsequent intracellular GSH synthesis [14]. Intracellular GSH acts as an antioxidant, neutralizing free radicals and so plays a decisive role in protection against oxidative stress during cell metabolism. Therefore, GGT and GSH are increasing in circumstances of oxidative stress like carcinogenesis [15].

However, analysis of the assessment of activity for lactate dehydrogenase, Gamma glutamyl transpeptidase and alkaline phosphatase in breast cancer has not yet been clear till now and many studies have tried to evaluate role of tumor markers in in diagnosis of carcinoma breast. The current study aim the possibility of using lactate dehydrogenase and Gamma glutamyl transpeptidase as screening tests among Sudanese women with breast cancer.

\section{Material and methods}

The present cross-sectional study was undertaken to determine biochemical changes in 50 carcinoma breast cases, they were attended to Khartoum oncology hospital for diagnosis, treatment and follow up. They were grade I, II and III. Approval of study to be performed was obtained from each patient and hospital administration as well. Under hygienic condition blood withdrawn in plane containers from each subject considering labeling and data obtained from each one, blood allowed for clot formation and subsequent serum separation which preserved at $-20{ }^{\circ} \mathrm{C}$ for later chemical analysis. Chemical analysis targeted enzymes, GGT and LDH, they measured by means of spectrophotometer method, using Biosystem device, reagents were Biosystem trademark, and they were ready to use [16].

\section{Results}

This study conducted in concern of breast cancer, it involved 50 women with established diagnosis, the Mean \pm SD duration of the disease was $(3.52+1.89)$ years and their age Mean \pm SD was $(38.1+6.31)$ years $($ Table -1$)$. They were enrolled in the measurement of GGT and LDH. Comparing the levels of measured parameters with normal value for each one, brought significant difference for LDH but no difference obtained for GGT (Table -2). Enzymes level among the three grades of breast cancer brought significant difference for LDH at grade II and III as p values 0.022 and 0.001 respectively, while GGT has only significant difference at grade III as p value 0.022 (Table -3).

Table 1 Age and duration of breast cancer

\begin{tabular}{llll}
\hline Parameters & Minimum & Maximum & Mean \pm SD \\
\hline Age (Years) & 26.00 & 49.00 & $38.10 \pm 6.31$ \\
Duration (Years) & 1.00 & 8.00 & $3.52 \pm 1.89$ \\
\hline
\end{tabular}

Table 2 Evaluation of GGT and LDH among breast cancer women

\begin{tabular}{llll}
\hline Parameters & Mean \pm SD & Mean (Normal Value) & P-value \\
\hline LDH (U/L) & $193.50 \pm 54.54$ & $337.5(225-450)$ & 0.000 \\
GGT (U/L) & $38.56 \pm 16.39$ & $41(34-48)$ & 0.298 \\
\hline \multicolumn{5}{c}{ Significant difference as p Value $<0.05$}
\end{tabular}


Zahra et al. / GSC Biological and Pharmaceutical Sciences 2019, 09(03), 064-068

Table 3 LDH and GGT among the three grades of breast cancer

\begin{tabular}{llll}
\hline Parameter & Grade I (Mean \pm SD) & Grade II (Mean \pm SD) & Grade III (Mean \pm SD) \\
LDH (U/L) & $128.66 \pm 14.04$ & $186.00 \pm 42.28$ & $204.86 \pm 59.14$ \\
P-value & 0.298 & 0.022 & 0.001 \\
GGT (U/L) & $28.66 \pm 13.31$ & $34.27 \pm 12.06$ & $42.24 \pm 18.24$ \\
P-value & 0.298 & 0.324 & 0.022 \\
\hline
\end{tabular}

\section{Discussion}

Breast cancer is the most common neoplasm affecting women in the Western world with approximately 1 in 11 developing the malignancy and 1 in 30 dying from the disease. For optimum management of these patients, assay of certain biochemical markers is necessary. Clinically, the most useful markers in breast cancer are the estrogen and progesterone receptors that are used to predict response to hormone therapy [17]. In the present study, serum levels of lactate dehydrogenase (LDH) and Gamma glutamyl -transpeptidase (GCT) were determined. As current study revealed, LDH were significantly increased at grades II and III as p values 0.022 and 0.001 respectively, as compared to normal values. These findings agreed with the studies of Mehdi et al. [18] and Talaiezadeh et al [19]. Our result also supported by some study mentions that level of LDHA is elevated in many malignant tumors and is associated with tumor proliferation and malignant growth, with potential implications for tumor diagnosis and therapy and The high activities of LDH in cancer cells may be due to the process of high cell proliferation, migration, or invasion than normal cells [20]. Our study also study revealed, Gamma glutamyl transpeptidase (GGT) were significantly increased only at grade III ( $p$ value 0.022). These observations were in agreement with the studies of Fentiman, et al. [21] and McElroy et al. [22]. Other study conducted by Basnyat et al, find that LDH and GGT showed steady and progressive increase in the activities of these enzymes from stage I-IV. The study concludes that serum LDH and GGT may be sensitive, specific and cost effective biomarkers in early diagnosis of breast cancer, assessing cancer prognosis and response to treatment [23]. Another study conducted by Rajeswari et al. and suggest that the estimation of LDH, GGT, and ALP can be used as routine screening tests in all suspected carcinoma breast patients and for general population and can detect metastasis [24]. Our study has some limitations, such as the relatively small number of subjects. Our finding on these result must be determined in further large scale controlled studies.

\section{Conclusion}

Significant elevation in serum levels of lactate dehydrogenase and Gamma glutamyl transpeptidase among patients with breast cancer and suggest that the estimation of both can be used as routine screening tests in all suspected carcinoma breast patients.

\section{Compliance with ethical standards}

\section{Acknowledgments}

The authors express gratitude to the Al-Neelain University, Faculty of Medical Laboratory Sciences, Also we are grateful thank all the patients and healthy who agreed to participate in this study.

\section{Disclosure of conflict of interest}

There is no conflict of interests between authors.

\section{References}

[1] Joe BN. Clinical features, diagnosis, and staging of newly diagnosed breast cancer.

[2] Siegel RL, Miller KD and Jemal A. (2019). Cancer statistics, CA Cancer J Clin, 69, 7. 
[3] Laronga C, Chagpar AB and Vora SR. (2016). Patient education: breast cancer guide to diagnosis and treatment (beyond the basics). UpToDate. UpToDate, Waltham, 7.

[4] Parkin DM, Bray F, Ferlay J and Pisani P. (2002). Global cancer statistics, CA Cancer J Clin, 55(2), 74-108.

[5] Beral V. (2003). Million Women Study Collaborators Breast cancer and hormone-replacement therapy in the Million Women Study. Lancet, 362, 419-427.

[6] Layde PM, Webster LA, Baughman AL, Wingo PA, Rubin GL and Ory HW. (1989).The independent associations of parity, age at first full term pregnancy, and duration of breastfeeding with the risk of breast cancer. Cancer and Steroid Hormone Study Group. J Clin Epidemiol, 42, 963-973.

[7] Hirschhaeuser F, Sattler UGa and Mueller-Klieser W. (2011). Lactate: a metabolic key player in cancer. Cancer Res, 71, 6921-6925.

[8] Maekawa M, Taniguchi T, Ishikawa J, Sugimura H, Sugano K and Kanno T. (2003). Promoter hypermethylation in cancer silences LDHB, eliminating lactate dehydrogenase isoenzymes 1-4. Clin Chem, 49, 1518-1520.

[9] Balch CM, Soong S, Atkins MB, Buzaid AC, Cascinelli N, Coit DG, Fleming ID, Gershenwald JE, Houghton A, Kirkwood JM, McMasters KM, Mihm MF, Morton DL, Reintgen DS, Ross MI, Sober A, Thompson JA and Thompson JF. (2004). An evidence-based staging system for cutaneous melanoma. CA Cancer J Clin 54, 131149 , quiz 182-184.

[10] Barlow LJ, Badalato GM. (2010). McKiernan JM Serum tumor markers in the evaluation of male germ cell tumors. Nat Rev Urol, 7, 610-617.

[11] Kazemi-Shirazi L, Endler G, Winkler S, Schickbauer T, Wagner O and Marsik C. (2007). Gamma glutamyltransferase and long-term survival: is it just the liver? Clin Chem, 53(5), 940-6.

[12] Whitfield JB. (2001). Gamma glutamyl transferase. Crit Rev Clin Lab Sci, 38(4), 263-355.

[13] Li S, Tan HY, Wang N, Zhang ZJ, Lao L, Wong CW and Feng Y. (2015). The role of oxidative stress and antioxidants in liver diseases. International journal of molecular sciences, 16(11), 26087-124.

[14] Zahra A. Ahmed, Abd Elkareem A. Rabo, Nagla Abdalhafez Mohamed and Asaad Ma. Babker. (2019). Assessment of the Activity of Lactate Dehydrogenase, Gamma Glutamyl Transpeptidase and Alkaline Phosphatase in Carcinoma Breast. EUROPEAN JOURNAL OF PHARMACEUTICAL AND MEDICAL RESEARCH, 6(12), 55-58.

[15] Duffy MJ. (2001). Biochemical markers in breast cancer: which ones are clinically useful?. Clinical biochemistry, 1, 34(5), 347-52.

[16] Mehdi M, Menon MKC, Seyoum N, Bekele M, Tigeneh W and Seifu D. (2018). Blood and Tissue Enzymatic Activities of GDH and LDH, Index of Glutathione, and Oxidative Stress among Breast Cancer Patients Attending Referral Hospitals of Addis Ababa, Ethiopia: Hospital-Based Comparative Cross-Sectional Study. Oxidative medicine and cellular longevity.

[17] Talaiezadeh A, Shahriari A, Tabandeh MR, Fathizadeh P and Mansouri S. (2015). Kinetic characterization of lactate dehydrogenase in normal and malignant human breast tissues. Cancer Cell International, 15(1), 19.

[18] Miao P, Sheng S, Sun X, Liu J and Huang G. (2013). Lactate dehydrogenase A in cancer: a promising target for diagnosis and therapy. IUBMB life, 65(11), 904-910.

[19] Fentiman IS and Allen DS. (2010). $\gamma$-Glutamyl transferase and breast cancer risk. British journal of cancer, 103(1), 90.

[20] McElroy JA, Shafer MM, Trentham-Dietz A, Hampton JM and Newcomb PA. (2006). Cadmium exposure and breast cancer risk. J Natl Cancer Inst, 98, 869-873.

[21] Basnyat AS, Jha A, Pathak R, Shrestha BG. (2017). Study of Serum Lactate Dehydrogenase and Gamma-Glutamyl Transpeptidase in Breast Cancer Patients receiving Chemotherapy. Journal of Tropical Life Science, 9, 7(2), 12832.

[22] Rajeswari G, Srinivas PS, Krishna Sai, KSR and Suresh E. (2016). Study of serum LDH and GGT levels in carcinoma breast. International Journal of Biomedical and Advance Research, 7(1), 31-34. 
Zahra et al. / GSC Biological and Pharmaceutical Sciences 2019, 09(03), 064-068

\section{How to cite this article}

Zahra AA, Abd Elkareem AR and Asaad MB. (2019). Using of lactate dehydrogenase and Gamma glutamyl transpeptidase as routine screening test among patients with breast cancer. GSC Biological and Pharmaceutical Sciences, 9(3), 64-68. 